Rev. Int. Contam. Ambie. 36 (4) 927-943, 2020

https://doi.org/10.20937/RICA.53776

\title{
ESTUDIO INTEGRAL DE LA CALIDAD DEL AGUA EN EL LITORAL DEL PUERTO SAN CARLOS, BAJA CALIFORNIA SUR, MÉXICO
}

Holistic study of water quality in the littoral of Puerto San Carlos, Baja California Sur, Mexico

\author{
Rafael CERVANTES-DUARTE ${ }^{1}$, Juan SANTOS-ECHEANDÍA ${ }^{2 *}$, \\ Juan J. RODRÍGUEZ-HERRERA ${ }^{3}$ and Ana J. MARMOLEJO-RODRÍGUEZ ${ }^{1}$
}

${ }^{1}$ Departamento de Oceanología, Instituto Politécnico Nacional, Centro Interdisciplinario de Ciencias Marinas (CICIMAR), Av. Instituto Politécnico Nacional s/n, Col. Playa Palo de Santa Rita, 23096 La Paz, Baja California Sur, México.

${ }^{2}$ Departamento de Contaminación Marina y Efectos Biológicos, Instituto Español de Oceanografía, Centro Oceanográfico de Vigo, Subida a Radio Faro 50, 36390 Vigo, España.

${ }^{3}$ Departamento de Tecnología de los Alimentos, Instituto de Investigaciones Marinas (IIM-CSIC), Eduardo Cabello 6, 36208 Vigo, España.

*Autor para correspondencia: juan.santos@ieo.es

(Recibido: octubre de 2019; aceptado: marzo de 2020)

Palabras clave: parámetros físicos y químicos, nutrientes, metales disueltos, bacterias coliformes, laguna costera.

\section{RESUMEN}

En marzo y noviembre de 2014 se llevaron a cabo mediciones de parámetros físicos, químicos y biológicos del agua superficial en 22 sitios del litoral de Puerto San Carlos (Bahía Magdalena, Baja California Sur, México), con el objetivo de evaluar la calidad del agua, identificar las posibles fuentes de contaminación y su estatus de acuerdo con la reglamentación mexicana. El área de estudio fue dividida en tres zonas según su actividad principal: 1) central termoeléctrica, 2) muelle fiscal portuario y (3) estero San Carlos, aledaño al poblado del mismo nombre. Los parámetros físicos, químicos y biológicos medidos fueron: temperatura, salinidad, oxígeno disuelto, clorofila-a, nutrientes, metales traza disueltos y bacterias coliformes. Los resultados mostraron una mala calidad del agua en las tres zonas estudiadas, de acuerdo con la NOM-001-SEMARNAT-1996 y los Criterios Ecológicos de Calidad del Agua CE-CCA-001/89, en particular con relación a los niveles de fosfato, amonio, silicato (no reglamentado) y la presencia de Escherichia coli. Las tres zonas se consideran fuentes de contaminación y su impacto es mayor en el mes más cálido y en mareas muertas, debido probablemente a la entrada de aguas contaminadas con derivados de residuos antrópicos. De acuerdo con las autoridades sanitarias del estado de Baja California Sur, la certificación de calidad del agua en Bahía Magdalena ha sido variable: en 2014 no fue certificada, mientras que en el periodo 2015-2017 fue nuevamente certificada. Esta región, que constituye un importante sitio de aprovechamiento pesquero y turístico, se encuentra en riesgo de contaminación debido a la falta de un sistema de tratamiento de aguas residuales en el poblado y a la inadecuada disposición de aguas grises y negras del puerto.

Key words: physical and chemical parameters, nutrients, dissolved metals, coliform bacteria, coastal lagoon. 


\begin{abstract}
Physical, chemical and biological parameters were measured in March and November 2014. These water analyses were carried out at 22 sites on the coast of Puerto San Carlos (Magdalena Bay, Baja California Sur, Mexico), with the objective of assessing water quality and identifying possible sources of water pollution and its status according to Mexican regulations. The study area was divided into three zones according to its main activity: (1) thermoelectric power station, (2) fiscal port harbor and (3) San Carlos estuary, adjacent to the to the town of the same name. The measured physical, chemical and biological parameters were temperature, salinity, dissolved oxygen, chlorophyll-a, nutrients, dissolved trace metals, and coliform bacteria. The results showed poor water quality in the three areas studied, in accordance with NOM-001-SEMARNAT-1996 and the ecological criteria for water quality CE-CCA-001/89, in particular regarding phosphate, ammonium, and silicate (unregulated) concentrations, as well as the presence of Escherichia coli. The three zones are considered sources of anthropogenic contamination whose impact is greater in the warmest month and dead tides, probably due to the entry of water contaminated by anthropogenic waste derivatives. According to the sanitary authorities of the state of Baja California Sur, the certification of water quality in Magdalena Bay has been variable: it was not certified in 2014, whilst in the period 2015-2017 it was re-certified. Although this region is an important touristic and fishing site, it is at risk of contamination due to the lack of a wastewater treatment system in the town and the inadequate disposal of raw sewage from the port.
\end{abstract}

\section{INTRODUCCIÓN}

Los cuerpos de agua costeros aledaños a las ciudades y poblados están sujetos a una elevada presión antrópica y por tanto se encuentran en constante riesgo de contaminación debido, entre otras causas, al impacto del uso del suelo por incremento de la población y servicios que ésta demanda, así como a la falta de sistemas de tratamiento de aguas residuales. Con mucho, el mayor de los desechos que ingresan en las aguas costeras y estuarios está compuesto de material orgánico, el cual está sujeto a ataque bacteriano (Clark 2001). Al ingresar al medio marino, los nutrientes inorgánicos derivados de nitrógeno (nitrito, nitrato, amonio) y fósforo (fosfato) son utilizados rápidamente por los productores primarios durante la fotosíntesis. Los aportes frecuentes de nutrientes de origen natural y/o antrópico a la zona costera pueden enriquecer el agua y promover el incremento masivo de especies de fitoplancton de baja calidad nutricional que, al morir, produce un abatimiento del oxígeno disuelto debido a la oxidación de la materia orgánica. Este proceso es denominado eutrofización y representa una amenaza para la biota en los sistemas costeros (Beiras 2018). Otro riesgo de contaminación para la zona costera son las actividades mineras e industriales que aportan elementos traza de origen natural o antrópico. Los metales y metaloides son contaminantes conservativos y sus adiciones al medio marino pueden ser permanentes (Clark 2001). Estos elementos están presentes de manera natural, aunque se presentan como impurezas en los sedimentos, y pueden ser transportados por el intemperismo de las rocas, siendo adsorbidos principalmente en partículas de oxihidróxidos de hierro (Fe) y manganeso $(\mathrm{Mn})$, así como en la materia orgánica. En determinadas condiciones físicas y químicas pueden ser liberados de los sedimentos a la columna de agua (Libes 2009, Santos-Echeandia et al. 2009a). A pesar de ser vistos principalmente como tóxicos potenciales, algunos forman parte de las funciones biológicas y de los ciclos biogeoquímicos dentro de los ecosistemas.

Las lagunas costeras, como Bahía Magdalena (Baja California Sur, México), son cuerpos de agua utilizados para la producción pesquera y acuícola regional. Además, son zonas turísticas aprovechadas para el avistamiento de aves y mamíferos marinos. En la parte interna de dicha bahía se localiza un puerto de altura utilizado principalmente para el transporte de petróleo y descarga de barcos pesqueros, especialmente sardineros, que vierten sus desechos a la laguna sin ningún tratamiento. Existe también una central termoeléctrica (CTE), la cual opera permanentemente para abastecer de energía eléctrica a la parte norte de la península. En la misma zona se localiza Puerto San Carlos, cuya población pasó de aproximadamente 4000 a 8000 habitantes en menos de una década. Al sureste de este poblado se localiza el estuario San Carlos (ESC), que es la vía de acceso para los pescadores ribereños. Todo ello ha 
generado un aumento de los servicios alimentarios, sanitarios, de energía y transporte, entre otros, y por lo tanto el deterioro de la calidad del recurso hídrico, principalmente en las zonas adyacentes a las fuentes de contaminación (Fig. 1).

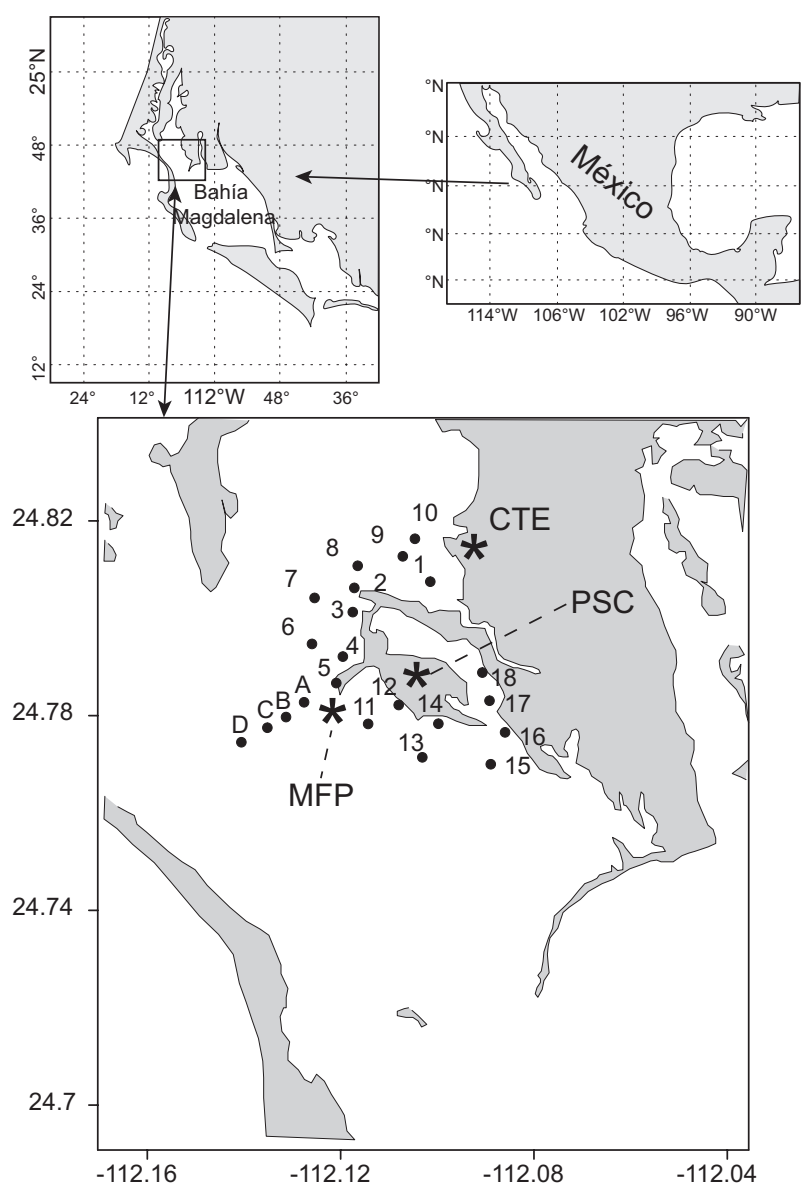

Fig. 1. Localización del área de estudio. Se señalan las tres zonas incluidas en el muestreo: Central Termo Eléctrica (CTE, estaciones 1-10), Muelle Fiscal Portuario (MFP, estaciones A, B, C y D), y poblado Puerto San Carlos (PSC, estaciones 11-18).

Desde el punto de vista geológico, la región adyacente a la laguna está compuesta de rocas ígneas, metamórficas y sedimentarias. En esta zona se explotan a cielo abierto yacimientos de fosforita, lo que contribuye a la contaminación de la laguna fosforo y otros elementos como cadmio, arsénico y uranio (Ahmad et al. 2014). El transporte de metales traza a la zona costera, derivado de las actividades mineras, puede ocurrir a través del viento del noroeste en invierno-primavera y por medio de arroyos estacionales, especialmente en la temporada de tormentas tropicales y ciclones (verano y otoño) (Shumilin et al. 2005).

Las características oceanográficas de la bahía han sido descritas por varios autores (Zaytsev y Cervantes-Duarte 2018), quienes han aportado información sobre la circulación, la velocidad de la corriente y la influencia estacional de las surgencias costeras, entre otros aspectos. El monitoreo de nutrientes inorgánicos disueltos ha mostrado el papel del aporte natural del océano y de otras fuentes antrópicas (Jiménez-Quiroz et al. 2019). El estudio inicial para la clasificación sanitaria del complejo lagunar Bahía Magdalena-Bahía Almejas determinó que la calidad sanitaria del agua y de moluscos se clasifica como aprobada en el $83 \%$ de los sitios analizados y como área prohibida en el $17 \%$ de éstos (PMSMB-CBCS 2009). De acuerdo con la Comisión Estatal para la Protección contra Riesgos Sanitarios (PMSMB-CBCS 2013), los productos acuícolas de áreas marinas que cuentan con certificación oficial de la calidad del agua tienen valor agregado en su exportación $\mathrm{s}$ mercados nacionales y extranjeros.

El presente estudio tiene como objetivo principal el análisis de la calidad del agua en distintas zonas del litoral del poblado de Puerto San Carlos, Baja California Sur, México, en dos épocas del año: marzo y noviembre de 2014.

\section{MATERIALES Y MÉTODOS}

En 2014 se realizaron dos campañas de muestreo, una el 19 de marzo durante la fase de mareas vivas y otra el 12 de noviembre durante las mareas muertas, con el propósito de averiguar si existen cambios en los parámetros físicos, químicos y biológicos asociados a las posibles fuentes de contaminantes, época del año y amplitud de la marea. En cada campaña se realizaron mediciones hidrológicas en 22 sitios (profundidad $\leq 2 \mathrm{~m}$ ) cerca del poblado de Puerto San Carlos. De acuerdo con las posibles fuentes de contaminación en el área, ésta se dividió en tres zonas: 1) CTE (estaciones 1-10), 2) muelle fiscal portuario (MFP) (estaciones A, B, C, D) y 3) estero San Carlos (ESC) (estaciones 11-18), aledaño al poblado del mismo nombre (Fig. 1). En cada sitio se obtuvieron datos de temperatura y salinidad por medio de un equipo CTD Seabird-19, y se recolectaron muestras de la superficie para nutrientes y metales disueltos por medio de bombeo peristáltico al vacío, mediante el cual las muestras fueron pasadas a través de un filtro de policarbonato de $0.45 \mu \mathrm{m}$. Asimismo, con 
una botella Niskin de $5 \mathrm{~L}$ se recolectaron muestras que se depositaron en frascos de demanda biológica de oxígeno (DBO) de $75 \mathrm{~mL}$ para determinar oxígeno disuelto (OD) y en frascos de $1 \mathrm{~L}$ para análisis de clorofila-a. Las muestras para análisis de bacterias se recolectaron por bombeo peristáltico directamente de la superficie del agua en frascos estériles sin pasar por el filtro y se mantuvieron en refrigeración hasta su análisis en laboratorio. Una vez en el laboratorio (18-24 h después de la toma), se filtraron al vacío $100 \mathrm{~mL}$ de la muestra contenida en cada frasco a través de un filtro de membrana de nitrato de celulosa estéril de $0.45 \mu \mathrm{m}$ de diámetro de poro, en cuya superficie quedaron retenidos los microorganismos. Tras filtrar cada una de las muestras, el filtro se depositó (boca arriba) sobre la superficie de una placa de agar cromogénico para coliformes (ACC) suplementado con vancomicina y cefsulodina para el análisis de coliformes y Escherichia coli. Las placas se incubaron seguidamente a $37^{\circ} \mathrm{C}$ durante $24-48 \mathrm{~h}$, tras de lo cual se contaron todas las colonias típicas que aparecieron sobre las membranas. Así, en el caso de los enterococos se contaron las colonias de color rojo marrón o rosas, mientras que en el agar cromogénico se contaron las colonias de color azul oscuro o violeta ( $ß$-galactosidasa positivas y $ß$-glucuronidasa positivas como $E$. coli) y las colonias de color rosa asalmonado o rojo (ß-galactosidasa positivas y $\beta$ glucuronidasa negativas como otras bacterias coliformes). El recuento de bacterias coliformes totales resultó de la suma de estos dos tipos de colonias.

La concentración de cada grupo de bacterias en agua de mar se calculó a partir del volumen de agua filtrado y el número de colonias características contadas sobre la membrana. Los resultados se expresan como unidades formadoras de colonias (UFC) por $100 \mathrm{~mL}$ (UFC/100 mL). Para recoger los nutrientes y metales se utilizaron frascos de plástico previamente lavados con HCl-diluído al $10 \%$. Los frascos para nutrientes fueron trasladados en hieleras a $4{ }^{\circ} \mathrm{C}$ y posteriormente congelados hasta su análisis en laboratorio, mientras que las muestras para metales fueron acidificadas a $\mathrm{pH} 2$ ( $\mathrm{HCl}$ Suprapur, Merck) una vez en el laboratorio y conservadas hasta su análisis en los mismos recipientes que se utilizaron en campo, realizando también blancos de muestreo. Las muestras para OD fueron analizadas de acuerdo con la técnica de Winkler (Parsons et al. 1984) y reportadas en porcentaje de saturación (Weiss 1970).

Las muestras de clorofila se filtraron al vacío sobre filtros de fibra de vidrio GF/F de $47 \mathrm{~mm}$ de diámetro; la extracción se realizó con acetona al $90 \%$ por 24 h en refrigeración (Venrick y Hayward 1984) y se midieron por espectrofotometría (Jeffrey y Humphrey 1975). Los nutrientes fueron analizados mediante las técnicas de Strickland y Parsons (1972) utilizando un espectrofotómetro Lambda 25 Perkin Elmer. El límite de detección por nutriente $(\mathrm{mg} / \mathrm{L})$ fue de $0.5 \times 10^{-3}$ para el nitrito, $3 \times 10^{-3}$ para el nitrato, $2 \times 10^{-3}$ para el amonio, $2.8 \times 10^{-3}$ para el fosfato $y$ $7.6 \times 10^{-3}$ para el silicato.

En el caso de los metales, las muestras fueron analizadas mediante técnicas electroquímicas como la voltamperometría de redisolución ánodica y catódica (Gardiner y Stiff 1975, Cobelo-García et al. 2005, Santos-Echeandia 2011) en una sala blanca, para evitar posible contaminación. Las muestras se manipularon siempre dentro de una cabina de flujo laminar. El límite de detección para metales fue de $0.002 \mu \mathrm{g} / \mathrm{L}$ para cadmio, $0.002 \mu \mathrm{g} / \mathrm{L}$ para cobalto), $0.006 \mu \mathrm{g} / \mathrm{L}$ para cobre, $0.030 \mu \mathrm{g} / \mathrm{L}$ para níquel, 0.022 $\mu \mathrm{g} / \mathrm{L}$ para plomo y $0.030 \mu \mathrm{g} / \mathrm{L}$ para zinc. Para evaluar la calidad del agua se compararon los valores máximos con la Norma Oficial Mexicana NOM-001CNA-1996 (SEMARNAT 1997) y con los Criterios Ecológicos de la Calidad del Agua CE-CCA-001/89 (SEDUE 1989). Asimismo, para averiguar si existían diferencias entre las temporadas de muestreo y entre zonas se realizó una prueba t de Student cuando la prueba de normalidad e igualdad de varianza fue aprobada; en caso contrario, se aplicó una prueba de suma de rangos de Mann-Whitney mediante el programa Sigma-Plot v. 11.0.

\section{RESULTADOS}

\section{Características termohalinas, oxígeno disuelto y clorofila-a}

La temperatura del agua en toda el área de muestreo varió de 20.5 a $23.2^{\circ} \mathrm{C}$ en marzo y de 23.4 a 25.5 ${ }^{\circ} \mathrm{C}$ en noviembre. El análisis entre épocas del año mostró que la temperatura en marzo fue significativamente menor respecto a noviembre $(\mathrm{t}=231 ; \mathrm{p}<$ $0.001)$. La salinidad en marzo y noviembre presentó un valor promedio global de $36.00 \pm 0.50 \%$ con valores mínimos en el MFP, y no presentó diferencias significativas $(\mathrm{t}=441 ; \mathrm{p}=0.618)$ (Cuadro I). La saturación de oxígeno varió de 83 a $121 \%$. No hubo diferencias significativas entre meses $(t=0.773 ; \mathrm{p}=$ 0.445). Las zonas del MFP y el ESC tendieron a ser más oxigenadas respecto a la CTE (Cuadro I). La clorofila-a en el área de estudio presentó un intervalo de variación de 1.1 a $4.7 \mu \mathrm{g} / \mathrm{L}$. No se registraron diferencias significativas entre meses $(t=-0.609 ; p$ $=0.547)$. El promedio en marzo fue de $3.0 \pm 1.1 \mathrm{y}$ 


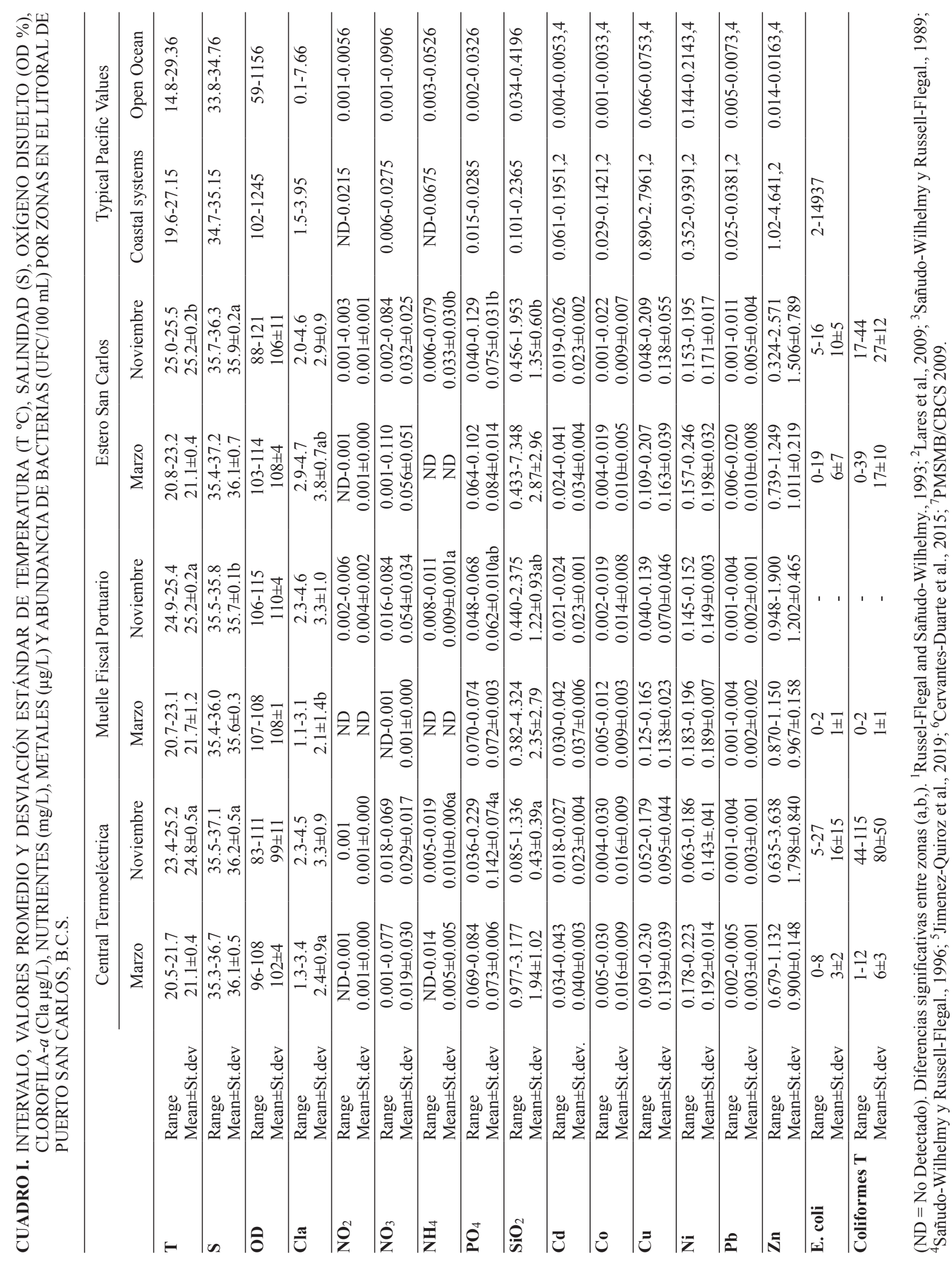


en noviembre de $3.2 \pm 0.9 \mu \mathrm{g} / \mathrm{L}$, con los valores más elevados en marzo en la zona del ESC (Cuadro I).

Si nos centramos en el muestreo de marzo, donde existían mareas vivas con una amplitud de aproximadamente $1 \mathrm{~m}$ por arriba del nivel medio del mar, la comparación por zonas mostró que la temperatura y la salinidad no presentaron diferencias significativas entre zonas:

Temperatura: CTE vs ESC: $\mathrm{t}=97, \mathrm{p}=0.069$; CTE vs MFP: $\mathrm{t}=24, \mathrm{p}=0.673$; ESC vs MFP: $\mathrm{t}=-0.383$, $\mathrm{p}=0.711$ ); salinidad (CTE vs ESC: $\mathrm{t}=-0.0208 ; \mathrm{p}=$ 0.984; CTE vs MFP: $t=1.466 ; p=0.171$; ESC vs MFP: $\mathrm{t}=1.061 ; \mathrm{p}=0.316$ ).

Saturación de oxígeno. Hubo diferencias significativas entre CTE y ESC: $t=95, p=0.100$. El resto de las zonas no presentaron diferencias significativas: CTE vs MFP: $\mathrm{t}=-1.582, \mathrm{p}=0.158$; ESC vs MFP: $\mathrm{t}$ $=-0.107, \mathrm{p}=0.918$.

Clorofila-a. Se observaron diferencias entre CTE y $\operatorname{ESC}(\mathrm{t}=-3.001, \mathrm{p}=0.013)$, pero no entre el resto de las zonas: CTE vs MFP: $\mathrm{t}=0.436, \mathrm{p}=0.678$; $\mathrm{ESC}$ vs MFP: $\mathrm{t}=2.409, \mathrm{p}=0.053$ (Cuadro I).

El muestreo de noviembre, sin embargo, se realizó durante mareas muertas, con una amplitud de marea $\leq 25 \mathrm{~cm}$ respecto del nivel medio del mar:

Temperatura: en la CTE fue significativamente menor que en el ESC $(t=101, p=0.029)$, aunque no hubo diferencias con el resto de las zonas: CTE vs MFP: $t$ $=44, \mathrm{p}=0.056$; ESC vs MFP: $\mathrm{t}=-0.292, \mathrm{p}=0.777$. Salinidad: en el MFP fue significativamente menor respecto de la CTE $(\mathrm{t}=2.348, \mathrm{p}=0.037)$ y el ESC $(\mathrm{t}=2.277, \mathrm{p}=0.046)$.

Saturación de oxígeno: no hubo diferencias significativas: CTE vs ESC: $\mathrm{t}=95, \mathrm{p}=0.100$; CTE vs MFP: $\mathrm{t}=-1.832, \mathrm{p}=0.094 ;$ ESCD vs MFP: $\mathrm{t}=-0.642$, $\mathrm{p}=0.537$.

Clorofila-a: tampoco hubo diferencias significativas entre las diferentes zonas: CTE vs ESC: $t=62, p$ $=0.230$; CTE vs MFP: $\mathrm{t}=33, \mathrm{p}=0.723$; ESCD vs MFP: $\mathrm{t}=-0.598, \mathrm{p}=0.563($ Cuadro I $)$.

\section{Nutrientes inorgánicos disueltos}

En marzo, durante las mareas vivas, los valores de nitrito $\left(\mathrm{NO}_{2}^{-}\right)$fluctuaron entre no detectado y $0.001 \mathrm{mg} / \mathrm{L}$, mientras que en noviembre con mareas muertas se presentaron valores de $0.001 \mathrm{mg} / \mathrm{L}$ en la CTE y ESC, y $0.004 \mathrm{mg} / \mathrm{L}$ en el MFP (Cuadro I). El nitrato $\left(\mathrm{NO}_{3}^{-}\right)$no presentó diferencias significativas por mes ni por zonas (CTE: $\mathrm{t}=208, \mathrm{p}=0.141$; ESC: $t=34, p=0.573$; MFP: $t=50, p=0.573)$. En marzo varió de 0.001 a $0.110 \mathrm{mg} / \mathrm{L}$, con los valores máximos en las estaciones 6, 11, 13 y 16 (Fig. 2a). En noviembre el intervalo de variación fue de 0.002 a $0.084 \mathrm{mg} / \mathrm{L}$, con valores máximos en las estaciones C y D del MFP, y 4, 5, 17 y 18 (Fig. 2b). El amonio $\left(\mathrm{NH}_{4}{ }^{+}\right)$fue significativamente menor en marzo que en noviembre $(t=130 ; p<0.001)$, y no presentó diferencias significativas entre zonas. Los valores más altos se registraron en los sitios 1 y 10 (Fig. 2c). En noviembre se presentaron concentraciones altas en las tres zonas (Fig. 2d), sin embargo, en el ESC las concentraciones fueron significativamente más altas respecto a la CTE y al MFP $(\mathrm{t}=27 ; \mathrm{p}=0.02)$ (Cuadro I). En la mayoría de los sitios el fosfato $\left(\mathrm{PO}_{4}{ }^{3-}\right)$ fue $>0.02 \mathrm{mg} / \mathrm{L}$ en los dos muestreos (Fig. 2e, f) y no presentó diferencias significativas entre ambos meses $(\mathrm{t}=260 ; \mathrm{p}=0.987)$. Los valores promedio por zona en marzo durante las mareas vivas no presentaron diferencias significativas, mientras que en noviembre durante las mareas muertas se observaron diferencias significativas solamente entre la CTE y el ESC ( $t$ $=2.379 ; \mathrm{p}=0.030$ ), correspondiendo a la CTE los valores más altos (Cuadro I). El silicato $\left(\mathrm{SiO}_{4}\right)^{4-}$ fue significativamente mayor en marzo que en noviembre $(\mathrm{t}=235 ; \mathrm{p}=0.015)$. En marzo la distribución por zonas no mostró diferencias significativas, mientras que en noviembre únicamente se observaron diferencias significativas entre la CTE y el ESC $(\mathrm{t}=3.877 ; \mathrm{p}=$ $0.001)$. El ESC presentó las mayores concentraciones y la mayor variabilidad (Cuadro I).

\section{Elementos traza disueltos}

Las concentraciones de $\mathrm{Pb}$ en el área de estudio variaron de 0.001 a $0.020 \mu \mathrm{g} / \mathrm{L}$ (Cuadro I), siendo los valores, por lo general, más elevados en la zona del ESC en ambas fechas, pero principalmente en el muestreo de marzo. Para las otras dos zonas de muestreo, los valores fueron similares en ambas épocas del año (Fig. 3a, b). Los niveles de Co variaron de 0.002 a $0.030 \mu \mathrm{g} / \mathrm{L}$ (Cuadro I), siendo los niveles ligeramente más elevados en la zona de la CTE que en las otras dos zonas (Fig. 3c, d). Para el Cd, las concentraciones estuvieron en el rango de 0.018 a $0.043 \mu \mathrm{g} / \mathrm{L}$ (Cuadro I), observándose valores por lo general más elevados en marzo que en noviembre, pero sin diferencias entre zonas (Fig. 3e, f).

El Cu presentó valores de un orden de magnitud superior a los tres metales anteriores, fluctuando entre 0.040 y $0.230 \mu \mathrm{g} / \mathrm{L}$ (Cuadro I), con niveles más altos por regla general en marzo que en noviembre, de manera similar al Cd (Fig. 4a, 4b). Los valores de Ni variaron de 0.063 a $0.246 \mu \mathrm{g} / \mathrm{L}$ (Cuadro I); por lo general, los valores promedio entre zonas de 

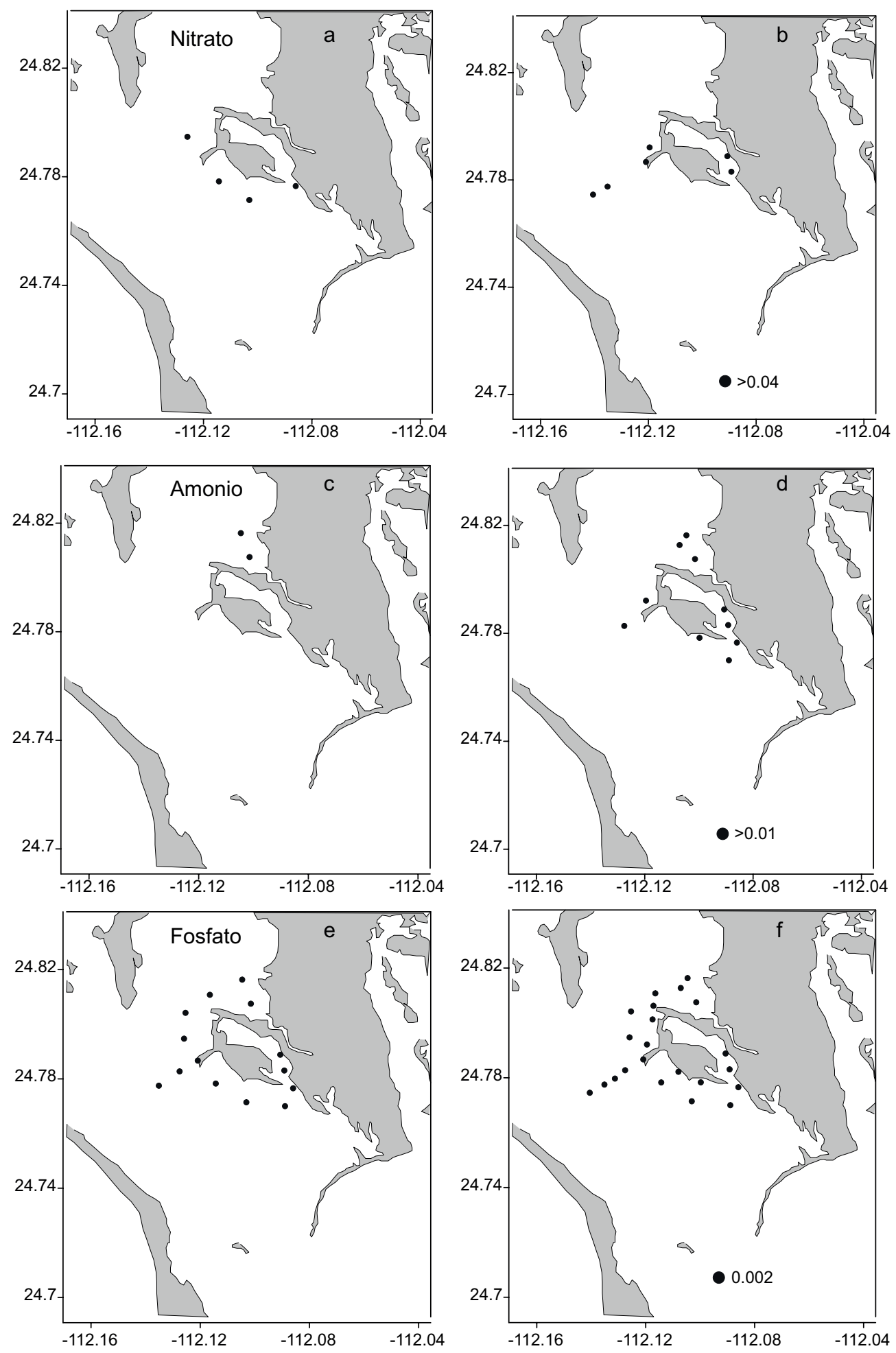

Fig. 2. Distribución de nutrientes $(\mathrm{mg} / \mathrm{L})$ que rebasan los criterios ecológicos, en $(\mathrm{a}, \mathrm{c}, \mathrm{e})$ marzo y (b, d, f) noviembre de 2014. 

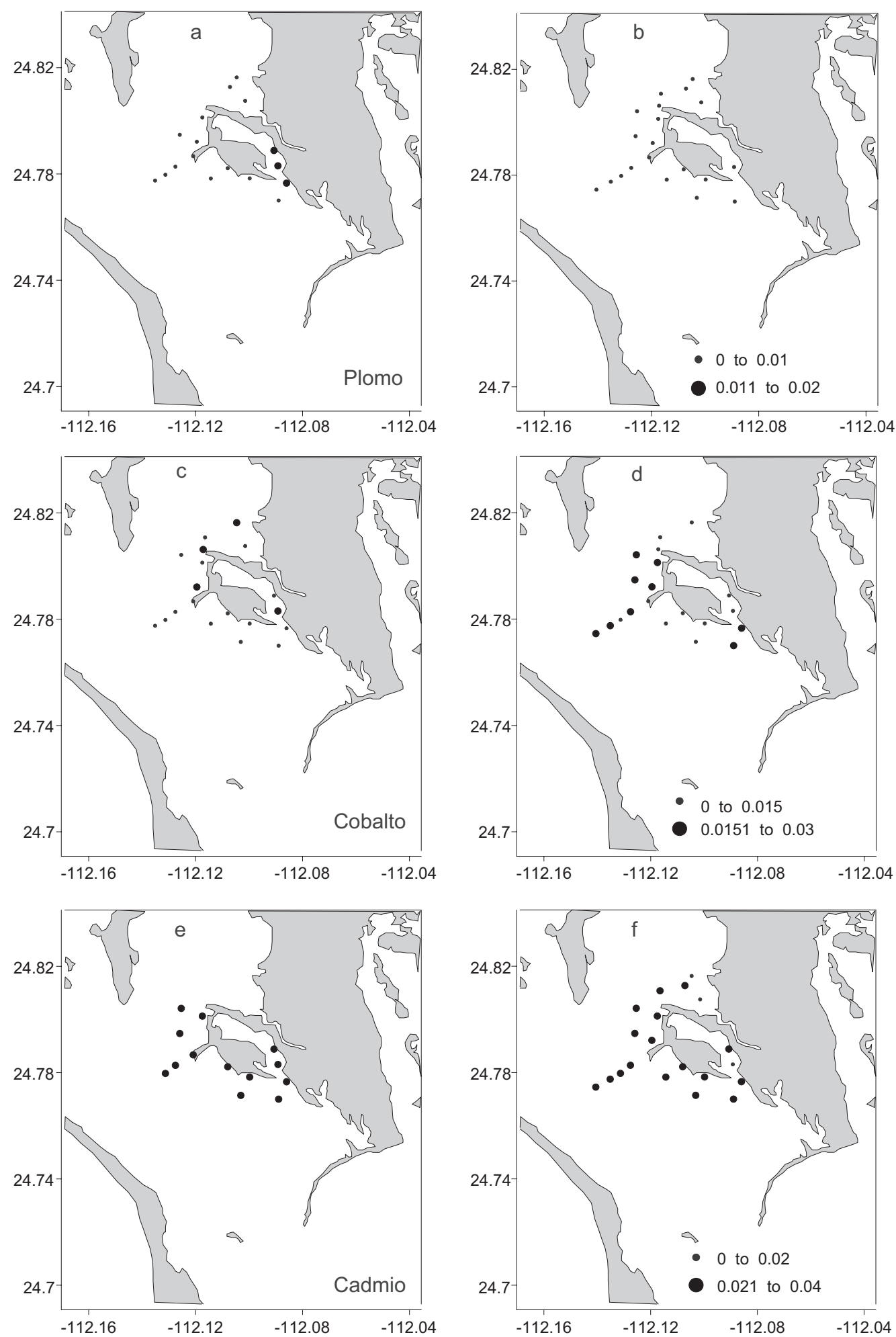

Fig. 3. Distribución de metales traza $(\mu \mathrm{g} / \mathrm{L})$ en el área de estudio en los meses de (a, c, e) marzo y (b, d, f) noviembre. 

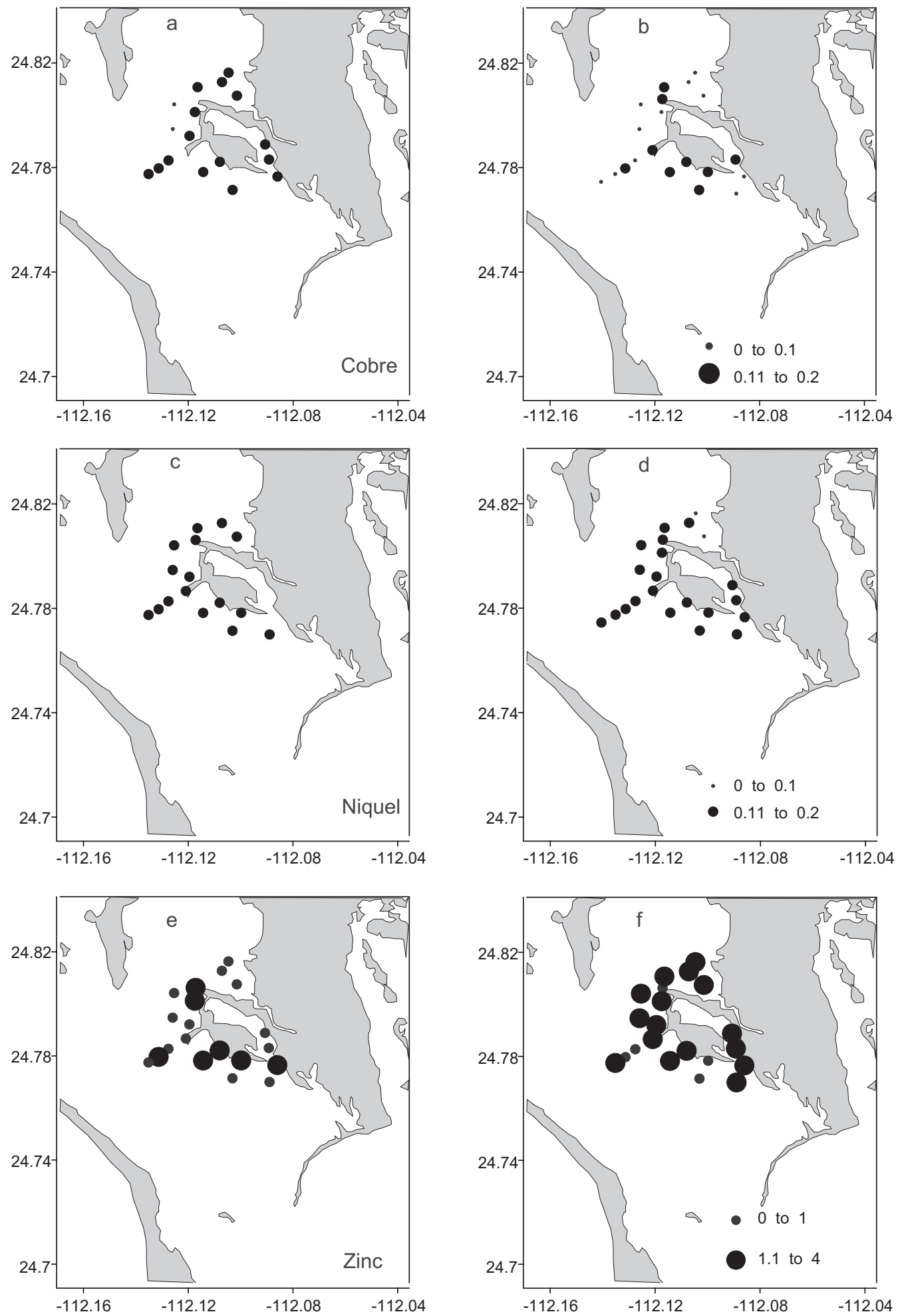

Fig. 4. Distribución de metales traza ( $\mu \mathrm{g} / \mathrm{L})$ en el área de estudio en los meses de (a, c, e) marzo y (b, d, f) noviembre. 
muestreo fueron muy similares pero ligeramente superiores en marzo (Fig. 4c, d). Finalmente, el Zn fluctuó en un rango de 0.324 a $3.638 \mu \mathrm{g} / \mathrm{L}$ (Cuadro I), siendo por regla general los valores más elevados en el muestreo de noviembre que en el de marzo, principalmente en la zona de la CTE (Fig. 4e, f).

\section{Recuento de bacterias (UFC/100 mL)}

Tanto en los muestreos de marzo como en los de noviembre se detectó la presencia de bacterias coliformes totales (Cuadro I). Los intervalos de abundancia en marzo fueron menores que en noviembre, con un máximo registrado en la CTE. La presencia de $E$. coli también fue detectada en ambos muestreos. En marzo el intervalo fue de no detectado a 19 con máximos en la zona ESC, particularmente en la estación 17 (interior del estero). En noviembre los máximos se registraron en la zona CTE (estación 9) con un intervalo de 5 a 27 en esta zona (Cuadro I).

\section{DISCUSIÓN}

\section{Efecto de la época del año y la amplitud de la marea}

La temperatura registrada en marzo $\left(21.6 \pm 0.8^{\circ} \mathrm{C}\right)$ fue significativamente menor que la registrada en noviembre, lo cual concordó con el promedio $\left(20.9{ }^{\circ} \mathrm{C}\right)$ reportado por Lluch-Belda et al. (2000) en el área de estudio para el periodo 1991-1998. En noviembre la temperatura fue más alta $\left(25.0 \pm 0.4^{\circ} \mathrm{C}\right)$ que el promedio anual reportado para la misma zona $\left(22.7^{\circ} \mathrm{C}\right)$. En este incremento pudo haber influido la presencia de un evento de calentamiento anómalo en la región oceánica del Pacifico conocido como The Blob, que se extendió desde el norte de Estados Unidos hasta la península de Baja California (Robinson 2016, Jiménez-Quiroz et al. 2019). En general, la salinidad en el área de estudio en ambos muestreos fue más alta que la reportada en otros sitios de Bahía Magdalena (Cervantes-Duarte et al. 2013). La alta evaporación y escaso aporte de agua dulce producen zonas hipersalinas en las zonas someras $(\leq 2 \mathrm{~m})$ de la laguna $(>36)$. Los intervalos de variación en ambos muestreos fueron similares (36.6 \pm 0.6 en marzo y $36.0 \pm 0.4$ en noviembre). La zona del canal de navegación que lleva al MFP presentó las menores salinidades en el estudio en marzo (35.6 \pm $0.3)$ y noviembre $(35.7 \pm 0.1)$, las cuales fueron más parecidas a las condiciones marinas; sin embargo, se consideran altas respecto a las reportadas en la boca que comunica al océano $(34.3 \pm 0.4)$ (CervantesDuarte et al. 2013, 2015) (Cuadro I). Los valores globales de saturación de oxígeno y la concentración de clorofila-a no variaron significativamente en el área de estudio; corresponden a condiciones predominantemente óxicas, relacionadas principalmente con la buena circulación del agua y la abundancia de productores primarios en la zona como macroalgas, fitoplancton, pastos, bosques de manglar y vegetación halófila (Funes-Rodríguez et al. 2007). No se observó riesgo por condiciones anóxicas en la zona de estudio. La clorofila-a promedio superficial fue relativamente alta $\left(3.1 \pm 1.0 \mathrm{mg} / \mathrm{m}^{3}\right)$ y presentó menos variación respecto de otras zonas someras de Bahía Magdalena durante el primer y segundo semestres $(2.8 \pm 2.5 \mathrm{y}$ $3.1 \pm 2.4 \mathrm{mg} / \mathrm{m}^{3}$, respectivamente) (Cervantes-Duarte et al. 2013), pero no con relación a la zona oceánica (Cuadro I).

En lo referente a nutrientes inorgánicos disueltos, el nitrito presentó la mayor concentración en las estaciones frente al MFP $(0.002 \mathrm{mg} / \mathrm{L}$; Cuadro II), de manera similar a lo reportado por Sujitha et al (2017) en la misma laguna, particularmente en las estaciones más cercanas a la costa y en el litoral de la zona de manglar. Los valores de nitrito tienden a incrementarse en condiciones de $\mathrm{pH}>8$, saturación de oxígeno $>95 \%$ y escasa iluminación (Dvir et al. 1999, Sujitha et al. 2017).

Los valores promedio de nitrato $(0.007 \mathrm{mg} / \mathrm{L})$ fueron menores a los reportados para esta laguna $(0.025 \mathrm{mg} / \mathrm{L})$ en el mes de octubre del mismo año por Sujitha et al. (2017), quienes mencionan que la única fuente de nitrato es la mezcla, advección y procesos de difusión del reservorio oceánico adyacente; sin embargo, la distribución de nitrito y nitrato presentada por estos autores mostró que los valores tendieron a incrementarse hacia la zona norte de la laguna (Fig. 5a-f). De forma análoga, los valores superiores a la norma encontrados en este estudio se observaron en el MFP y el ESC (Fig. 2a, b), lo cual podría indicar una fuente antrópica.

Los valores de amonio fueron significativamente menores en mareas vivas, ya que pasaron de 0.002 $\pm 0.004 \mathrm{mg} / \mathrm{L}$ en marzo a $0.019 \pm 0.022 \mathrm{mg} / \mathrm{L}$ en noviembre, especialmente en la zona del ESC. Este aumento puede estar relacionado con el aporte de agua residual del poblado de Puerto San Carlos, que es más evidente durante las mareas muertas y en una estación del año más cálida. Aunque las fuentes y sumideros de amonio en el mar son biogénicas, los agentes físicos como la temperatura, luz y oxigenación son de considerable importancia en la determinación de la concentración de este elemento (Badran 2001).

El intervalo de concentración de fosfato $(0.012$ a $0.075 \mathrm{mg} / \mathrm{L}$ ) fue mayor al reportado en la laguna 
por Sujitha et al. (2017) (0.005 a $0.045 \mathrm{mg} / \mathrm{L})$; estos autores sugieren que las altas concentraciones de fosfato se deben a una rápida mineralización y alto $\mathrm{pH}(8.28)$ en las aguas subyacentes que provocan la liberación de fosfato de los sedimentos aeróbicos al agua intersticial y posteriormente a la columna de agua.

En ambos muestreos (marzo y noviembre), el silicato presentó las concentraciones más elevadas respecto a la zona costera y océano adyacente (Cuadro I). La fuente principal de sílice en la laguna puede ser marina (por surgencia de agua subsuperficial) y terrestre a partir de transporte por el viento. En marzo de 2014 se registró un fenómeno meteorológico anómalo en el sur de la Península de Baja California, con vientos excepcionalmente fuertes (hasta 60 $\mathrm{km} / \mathrm{h}$ ), lo cual puede haber contribuido a la mayor concentración reportada. Los silicatos son tomados principalmente por organismos planctónicos (diatomeas y radiolarios) que al morir llevan al fondo el silicato biogénico. Los cambios en los patrones de viento y la circulación a gran escala promueven los cambios estacionales del fitoplancton. Las diatomeas tienden a dominar de marzo a junio debido al aporte de nutrientes por surgencias (Martínez-López y Verdugo-Díaz 2000). Asimismo, se han obtenido correlaciones significativas entre la temperatura del agua y el silicato con la abundancia celular de las diatomeas (Jiménez-Quiroz et al. 2019).

Los metales traza en el área de estudio presentaron valores coherentes con los niveles de metales en aguas de otros sistemas costeros de la zona (Russel-Flegal y Sañudo-Wilhelmy 1993, Lares et al. 2009) y con los valores típicos de aguas del Océano Pacífico (SañudoWilhelmy y Russell-Flegal 1989, Sañudo-Wilhelmy y Russell-Flegal 1996). En el caso del Cd, las concentraciones encontradas en este estudio varían de $0.018 \mathrm{a} 0.043 \mu \mathrm{g} / \mathrm{L}$, que son valores intermedios entre los típicos del Océano Pacífico (0.004-0.005 $\mu \mathrm{g} / \mathrm{L})$ y los encontrados en otros sistemas costeros del Pacífico mexicano (0.061-0.195 $\mu \mathrm{g} / \mathrm{L})$ (Cuadro I). Si se observan los valores de Co (0.001-0.030 $\mu \mathrm{g} / \mathrm{L})$, los niveles vuelven a ser mayores que los típicos de aguas del Pacífico (0.001-0.003 $\mu \mathrm{g} / \mathrm{L}$ ), aunque iguales o menores que los medidos en sistemas costeros similares (0.029-0.142 $\mu \mathrm{g} / \mathrm{L})$. Atendiendo al $\mathrm{Cu}$, los valores encontrados en este estudio $(0.040-0.230 \mu \mathrm{g} / \mathrm{L})$ se encuentran entre los típicos de aguas del Pacífico (0.066-0.075 $\mu \mathrm{g} / \mathrm{L})$ y los de otros sistemas costeros cercanos $(0.890-2.796 \mu \mathrm{g} / \mathrm{L})$. En cuanto a los valores de Ni, se sitúan en niveles muy cercanos a los valores típicos de aguas del Pacífico (0.144-0.214 $\mu \mathrm{g} / \mathrm{L})$ y siempre por debajo de los encontrados en otros sistemas costeros de similares características $(0.352$ $0.939 \mu \mathrm{g} / \mathrm{L})$. Los valores de $\mathrm{Pb}$ en el litoral de Puerto San Carlos (0.001-0.020 $\mu \mathrm{g} / \mathrm{L})$ son muy cercanos a los valores típicos oceánicos $(0.005-0.007 \mu \mathrm{g} / \mathrm{L})$ y siempre menores a los valores medidos de sistemas costeros próximos $(0.025-0.038 \mu \mathrm{g} / \mathrm{L})$. Finalmente, en el caso del Zn (0.324-3.638 $\mu \mathrm{g} / \mathrm{L})$, los niveles son un orden de magnitud superiores a los de aguas oceánicas del Pacífico $(0.014-0.016 \mu \mathrm{g} / \mathrm{L})$ y muy similares a los encontrados en sistema costeros de la zona $(1.02-4.64 \mu \mathrm{g} / \mathrm{L})$. Atendiendo a las normas y criterios ecológicos (Cuadro II), los niveles de metales encontrados en este estudio no superan en ningún caso a los establecidos en la legislación mexicana. Únicamente el Cd (con un nivel promedio de $0.03 \pm$ $0.02 \mu \mathrm{g} / \mathrm{L}$ y valores puntuales de $0.04 \mu \mathrm{g} / \mathrm{L}$ ) presenta valores cercanos a los establecidos en los Criterios Ecológicos de la Calidad del Agua $(0.09 \mu \mathrm{g} / \mathrm{L})$ para este metal (SEDUE 1989).

Por tanto, desde el punto de vista de los metales disueltos en agua no existe una amenaza real para el ecosistema lagunar de Bahía Magdalena, en concreto en la zona cercana a Puerto San Carlos, que es donde se centra este estudio. Sin embargo, es de especial interés resaltar las diferencias existentes entre algunos de los metales en ambas épocas de muestreo, correspondientes además con diferentes momentos de marea. En este sentido, los niveles de promedio de $\mathrm{Cd}, \mathrm{Cu}$ y Ni presentaron niveles significativamente más elevados en marzo $(p<0.05)$ durante mareas vivas que en noviembre. En el caso del $\mathrm{Cd}$, los valores disminuyeron de $0.037 \pm 0.005 \mu \mathrm{g} / \mathrm{L}$ en marzo a $0.023 \pm 0.003 \mu \mathrm{g} / \mathrm{L}$ en noviembre. Para el $\mathrm{Cu}$, la disminución fue de $0.148 \pm 0.037 \mu \mathrm{g} / \mathrm{L}$ en marzo a $0.106 \pm 0.053 \mu \mathrm{g} / \mathrm{L}$ en noviembre. Finalmente, el descenso del Ni fue de $0.194 \pm 0.023 \mu \mathrm{g} / \mathrm{L}$ en marzo a $0.154 \pm 0.031 \mu \mathrm{g} / \mathrm{L}$ en noviembre. La resuspensión de sedimentos ricos en metales de la laguna con las corrientes de marea puede ser la causa de este aumento en los niveles, al menos del $\mathrm{Cd}$ y el Ni, en época de mareas vivas. Un estudio de Rodríguez-Meza et al. (2007) mostró niveles de Cd en el sedimento lagunar $(0.1-0.5 \mathrm{mg} / \mathrm{kg})$ superiores a los niveles de la corteza terrestre (0.09; Rudnick y Gao 2003). Estas altas concentraciones en los sedimentos lagunares proceden probablemente de las rocas fosfatadas aportadas por la cuenca Las Bramonas (situada al norte de Puerto San Carlos), cuyo contenido de $\mathrm{Cd}$ es de aproximadamente $100 \mathrm{mg} / \mathrm{kg}$ (González-Soto. 2017). Algo similar ocurre para el $\mathrm{Ni}$, ya que Rodríguez-Meza et al. 2007 midieron concentraciones de $1-119 \mathrm{mg} / \mathrm{kg}$ cuando los niveles de la corteza terrestre son de $47 \mathrm{mg} / \mathrm{kg}$ (Rudnick y Gao 


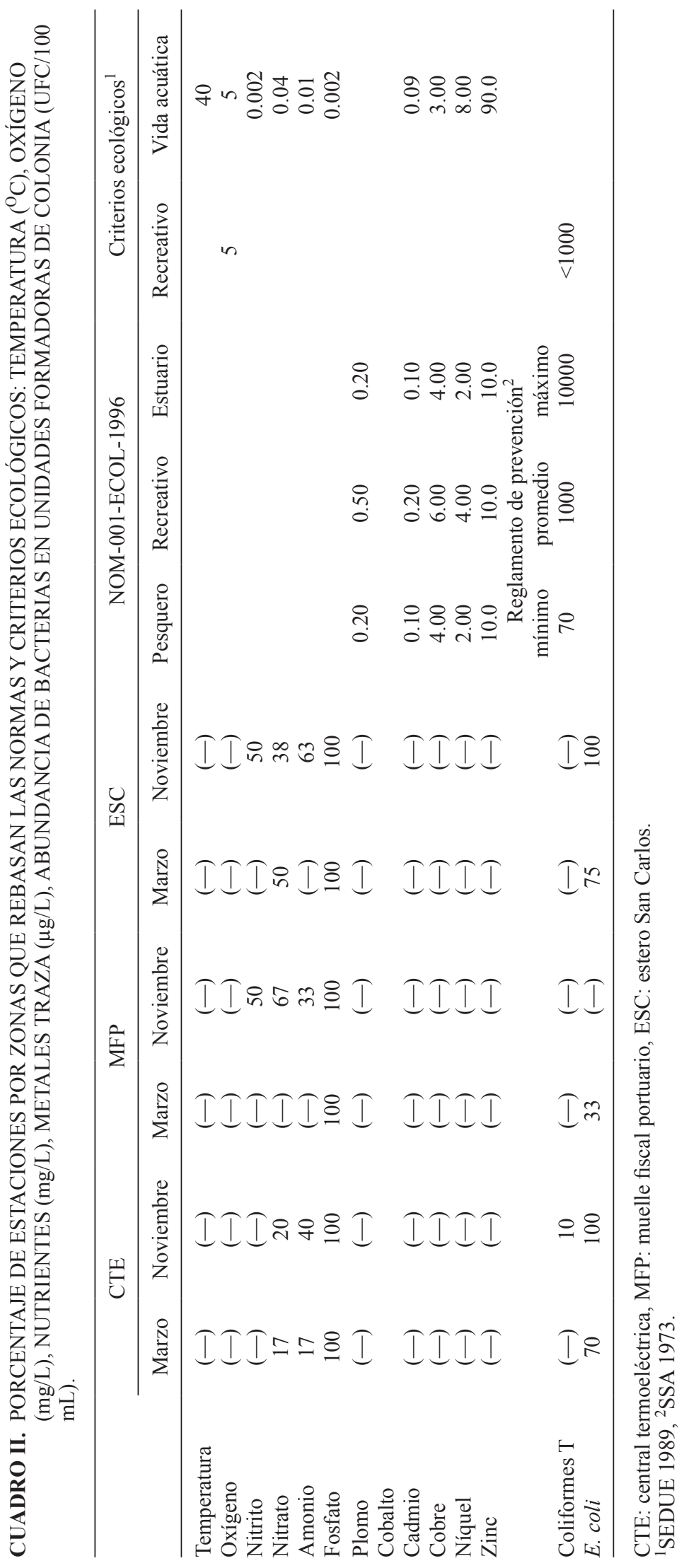


2003). Esta resuspensión puede actuar de dos formas: en primer lugar, aumentando los flujos bentónicos de metales desde el agua intersticial hacia la columna de agua (Santos-Echeandia et al. 2009a) y, en segundo lugar, poniendo en suspensión partículas ricas en metales que pueden provocar una redisolución de los mismos desde la fase particulada a la disuelta. Esto es especialmente importante en el caso del Cd, que tiene una tendencia importante a la fracción disuelta a salinidades elevadas como las encontradas en este estudio $(35.6 \pm 0.3)$ con relación a estudios previos en la boca que comunica al océano (34.3 \pm 0.4; Cervantes-Duarte et al. 2013). Esto se debe a la elevada afinidad del $\mathrm{Cd}$ por los cloruros, como se ha demostrado en trabajos previos (Santos-Echeandia et al. 2009b).

En el caso de $\mathrm{Cu}$, no parece que los sedimentos sean la fuente principal de este metal en el agua, ya que los valores típicos del sedimento de Bahía Magalena varían de 0.1 a $33 \mathrm{mg} / \mathrm{kg}$ (RodríguezMeza et al. 2007), y son similares o inferiores a los valores de fondo $(28 \mathrm{mg} / \mathrm{kg})$ de la corteza continental (Rudnick y Gao 2003). Los niveles encontrados en agua en el presente estudio son, además, del orden de los valores típicos de aguas oceánicas del Pacífico (Sañudo-Wilhelmy y Russell-Flegal 1989, 1996). Por tanto, las diferencias entre el muestreo de marzo y el de noviembre pueden explicarse por la clorofila. En este sentido, los mayores niveles de clorofila de noviembre $(3.16 \pm 0.91)$ respecto a marzo $(2.96 \pm$ 1.09) son indicativos de una mayor cantidad de organismos fitoplantónicos que utilizan el $\mathrm{Cu}$ disuelto en el medio para su metabolismo (Raven et al. 1999) y por lo tanto lo estarían retirando del medio.

El Zn presenta un comportamiento opuesto al de los tres metales anteriores respecto a la marea, ya que se encontraron valores significativamente más bajos en marzo $(0.95 \pm 0.17 \mu \mathrm{g} / \mathrm{L})$ que en noviembre $(1.58 \pm 0.77 \mu \mathrm{g} / \mathrm{L})(\mathrm{p}<0.05)$. Los mayores niveles de este metal observados durante el muestreo en mareas muertas apuntan a la entrada de aguas subterráneas residuales a la bahía asociada a los pozos negros como fuente principal, como han mostrado estudios previos en otras zonas costeras (Trezzi et al. 2016). Los valores de unidades formadoras de colonias en el caso de las bacterias corroboran esta teoría sobre la entrada de aguas subterráneas durante mareas muertas, ya que tanto para los coliformes totales como para $E$. coli en particular, son significativamente más elevados $(\mathrm{p}<0.05)$ en el muestreo de noviembre. Además, una de las principales fuentes de entrada antrópica de $\mathrm{Zn}$ a los sistemas costeros son las industrias de galvanoplastia (Araújo et al. 2017).
Finalmente, los dos elementos restantes, el Co y el $\mathrm{Pb}$, no mostraron diferencias significativas entre los muestreos. Los valores de Co en marzo y noviembre fueron de $0.012 \pm 0.007$ y $0.013 \pm 0.008 \mu \mathrm{g} / \mathrm{L}$, respectivamente. En el caso del $\mathrm{Pb}$, los niveles fueron de $0.006 \pm 0.006 \mu \mathrm{g} / \mathrm{L}$ en marzo y de $0.004 \pm 0.003$ $\mu \mathrm{g} / \mathrm{L}$ en noviembre. Los niveles de ambos elementos en el litoral de Puerto San Carlos son similares a los valores típicos de aguas del Océano Pacífico (SañudoWilhelmy y Russell-Flegal, 1996) por lo que no parece haber ninguna fuente antrópica en la zona que afecte los niveles de estos elementos. En tal caso, de manera similar al $\mathrm{Cu}$, los niveles más bajos de Co en el muestreo de noviembre pueden estar asociados con su incorporación por parte del fitoplancton, ya que es un elemento esencial utilizado para los procesos metabólicos de estos organismos (Sunda y Huntsman 1995).

\section{Fuentes de contaminación en la zona}

La zona norte de Bahía Magdalena concentra la mayor actividad antrópica, conformada por la CTE, el MFP y la población aledaña al ESC. En las tres zonas analizadas no se observó un efecto termohalino asociado con alguna fuente de contaminación. Por ejemplo, no se detectó la pluma de agua caliente del sistema de enfriamiento de la CTE, que es vertida a la laguna por un emisor sumergido, ni algún proceso de dilución del agua marina por aporte de agua dulce en la zona del MFP y el ESC. Asimismo, el oxígeno disuelto presentó en ambos muestreos valores por arriba del valor límite de $5 \mathrm{mg} / \mathrm{L}$ (SEDUE 1989). En general, los valores están cercanos al valor de saturación (Cuadro II). Los iones nutrientes presentaron un gradiente de concentración nitrito $<$ nitrato $<$ amonio $<$ fosfato $<$ silicato que indican una mayor utilización de nitrógeno inorgánico por los productores primarios y una mayor disponibilidad de fosfato y silicato. De acuerdo con los Criterios Ecológicos de la Calidad del Agua (SEDUE 1989), en noviembre el nitrito rebasó el valor establecido $(0.002 \mathrm{mg} / \mathrm{L})$ en el MFP y el ESC en $50 \%$ de las muestras (Cuadro II). Para el nitrato y el amonio, los valores límite de $0.04 \mathrm{mg} / \mathrm{L} \mathrm{y}$ $0.01 \mathrm{mg} / \mathrm{L}$ fueron rebasados en noviembre y al menos en dos de las tres zonas en marzo (Cuadro II). El fosfato rebasó el límite permitido $(0.002 \mathrm{mg} / \mathrm{L})$ en el $100 \%$ de las muestras, por lo que este nutriente es un componente no limitante para los productores primarios de la laguna (Cervantes-Duarte et al. 2012). En este estudio, los niveles altos de nitrito y amonio en mareas muertas están relacionados con la fuente de aguas residuales y procesos de descomposición de materia orgánica in situ; sin embargo, con valores de $\mathrm{pH}>8$, condiciones de saturación de oxígeno y 
buena iluminación pueden contribuir a incrementar la concentración de nitrito (Dvir et al. 1999, Sujitha et al. 2017). Por otra parte, en mareas vivas la fuente de fosfato y silicato estuvo relacionada con la fuente local antrópica y la fuente natural aledaña al área de estudio; por ejemplo, en el caso del fosfato, al aporte de detergentes y productos de limpieza, así como el guano de las aves. Además, en Bahía Magdalena la presencia de bosques de manglar y depósitos de fosforita en las áreas vecinas puede ser el principal factor responsable de los altos niveles de fosfato en el fondo y cerca de la costa (Sujitha et al. 2017). En cuanto al silicato, las fuentes principales son la arena de dunas adyacentes que son transportadas por el viento, especialmente en invierno-primavera, y la resuspensión del sedimento del fondo durante las mareas vivas. Las bacterias coliformes totales estuvieron presentes en un elevado número de muestras, pero sin rebasar los niveles establecidos en las normativas mexicanas. Sin embargo, E. coli sí superó los niveles en las tres zonas estudiadas. Por último, los metales medidos no superaron en ninguna de las estaciones las normativas mexicanas.

El MFP es uno de los tres puertos de altura del estado de Baja California Sur. De manera constante atracan en él barcos pesqueros con captura de los recursos de la región, como sardina y anchoveta, así como barcos de mayor calado para la pesquería de atún en la costa del Pacífico. La industria de la sardina continuamente descarga el producto en el puerto y genera un volumen considerable de residuos que son vertidos al mar sin tratamiento alguno. Estos residuos generan espuma nociva en la superficie del agua, que proviene de los químicos que se usan en el proceso de conservación del pescado. Otras embarcaciones de gran calado que habitualmente atracan en el puerto son los buques tanque que transportan hidrocarburos del petróleo para la CTE y las embarcaciones de la Armada de México. Las principales fuentes de contaminación en esta zona son los derrames de petróleo; grasas y aceites; , nitrito y amonio por contaminación orgánica reciente; fósforo proveniente de la roca fosfórica (Rodríguez-Meza et al. 2007) y del guano de las aves residentes y migratorias (Zárate-Ovando et al. 2006), y E. coli de posible origen antrópico.

El ESC se encuentra impactado por los desechos del poblado de Puerto San Carlos, con una población de aproximadamente 8 mil habitantes que carecen de una planta de tratamiento de aguas residuales. A esto se añade un sistema de alcantarillado que bombea el agua directamente al estero cuando hay inundación en la época de tormentas tropicales y ciclones. En consecuencia, el ESC está en riesgo continuo de contaminación debido a que los servicios sanitarios del poblado funcionan con fosas sépticas (secas y húmedas) y letrinas. Otras importantes fuentes de contaminación en el ESC son los desechos sólidos y líquidos derivados de la pesca artesanal que se lleva a cabo en las rampas de embarque de los pescadores, y el relleno sanitario que se encuentra fuera del poblado. Los valores de $\mathrm{Pb}$ son relativamente más altos en el ESC, donde el aporte de dicho metal puede provenir de la embarcaciones menores (pangas) de los pescadores ribereños de Bahía Magdalena, las cuales tiene su base en el ESC. Aproximadamente circulan diariamente alrededor de 100 pangas y en temporada de pesca de camarón su número se incrementa hasta 500 (Rábago-Quiroz et al. 2017). De manera similar al $\mathrm{Pb}$, la entrada de Ni puede estar asociada con las actividades de las embarcaciones, ya que es un producto de la combustión. De hecho, existe una correlación positiva y significativa $(\mathrm{r}=$ $0.67 ; \mathrm{n}=40$ ) entre los valores de $\mathrm{Pb}$ y Ni disueltos.

\section{CONCLUSIONES}

La calidad del agua en el litoral de Puerto San Carlos registrada en marzo (mareas vivas) y noviembre (mareas muertas) de 2014 fue mala de acuerdo con los límites establecidos en la Norma Oficial Mexicana NOM-001-SEMARNAT-1996 (SEMARNAT 1997) y los Criterios Ecológicos de Calidad del Agua CE-CCA-001/89 (SEDUE 1989), y coincidió con el dictamen de no certificación expedido ese año (PMSMB-CBCS 2013). Sin embargo, los niveles de saturación de oxígeno fueron generalmente cercanos al $100 \%$ y correspondieron a la alta biomasa de fitoplancton estimada por la concentración de clorofila-a. El exceso de nitrógeno inorgánico (nitrito y amonio) y fosfato contribuyó a la observación de la mala calidad del agua. Asimismo, en varias de las estaciones se detectó la presencia de E. coli, un indicador de contaminación antrópica, en concentraciones superiores a las establecidos por las normativas. Aunque en 2015 y 2016 la certificación fue nuevamente aprobada (PMSMB-CBCS 2015), tanto el agua y como los productos extraídos están en continuo riesgo de contaminación debido a la falta de sistemas de tratamiento de aguas residuales y a la descarga de aguas grises y negras en el Puerto y en el muelle turístico del ESC. Mientras no haya una planta de tratamiento de aguas residuales en el poblado y los vertimientos de la CTE, el MFP y el ESC no sean tratados, existirá el riesgo potencial de contaminación en Bahía Magdalena. 


\section{AGRADECIMIENTOS}

Agradecemos a las instituciones de investigación españolas y mexicanas por el apoyo brindado para la realización de este estudio. Asimismo, al Consejo Superior de Investigaciones Científicas (CSIC) y al Instituto Politécnico Nacional (IPN) por el otorgamiento de recursos para los proyectos 2013CD0014 y SIP-20140850, respectivamente. También a la Dra. Rodríguez-Figueroa por su apoyo en el muestreo y pretratamiento de muestras y al Dr. Cobelo-García por la realización de pruebas analíticas.

\section{REFERENCIAS}

Ahmad F., Farouk S. y Abd El-Moghny M.W. (2014). A regional stratigraphic correlation for the upper Campanian phosphorites and associated rocks in Egypt and Jordan. P. Geol. Assoc. 125, 419-431. https://doi. org/10.1016/j.pgeola.2014.06.002

Araújo D.F., Boaventura G.R., Machado W., Viers J., Weiss D., Patchineelam S.R., Ruiz I., Rodrigues A.P.C., Babinski M. y Dantas E. (2017). Tracing of anthropogenic zinc sources in coastal environments using stable isotope composition. Chem. Geol. 449, 226-235. https://doi.org/10.1016/j.chemgeo.2016.12.004

Badran M.I. (2001). Dissolved oxygen, chlorophyll- $a$ and nutrients: Seasonal cycles in waters of the gulf of Aquaba, Red Sea. Aquat. Ecosyst. Health 4 (2), 139150. https://doi.org/10.1080/14634980127711

Beiras R. (2018). Marine Pollution. 1a ed. Elsevier, Ámsterdam, $408 \mathrm{pp}$.

Cervantes-Duarte R., López-López S., Aguirre-Bahena F., González-Rodríguez E. y Futema-Jiménez S. (2012). Relevancia de fuentes nitrogenadas nuevas y regeneradas en la columna de agua en Bahía Magdalena (SO) Península de Baja California, México. Rev. Biol. Mar. 47 (3), 587-592. https://doi.org/10.4067/S071819572012000300021

Cervantes-Duarte R., Prego R., López-López S., AguirreBahena F. y Ospina-Álvarez N. (2013). Annual patterns of nutrients and chlorophyll in a subtropical coastal lagoon under the upwelling influence (SW of Baja California Peninsula). Estuar. Coast. Shelf S. 120, 5463. https://doi.org/10.1016/j.ecss.2013.01.020

Cervantes-Duarte R., Prego R., Gaxiola-Castro G., LópezLópez S., Aguirre-Bahena F. y Murillo-Murillo I. (2015). Intra-annual upwelling patterns and its linkage with primary production in the euphotic zone $\left(24.5^{\circ} \mathrm{N}\right)$ of Southern Baja California coast. Estuar. Coast. Shelf S. 157, 51-58. https://doi.org/10.1016/j. ecss.2015.02.008
Clark R.B. (2001). Marine Pollution. 5a ed. Oxford University Press, Oxford, Reino Unido, 237 pp.

Cobelo-García A., Santos-Echeandía J., Prego R. y Nieto O. (2005). Direct simultaneous determination of $\mathrm{Cu}, \mathrm{Ni}$ and $\mathrm{Y}$ in seawater using adsorptive cathodic stripping voltammetry with mixed ligands. Electroanal. 17 (10), pp. 906-911. https://doi.org/10.1002/elan.200403203

Dvir O., Van-Rijn J. y Neori A. (1999). Nitrogen transformations and factors leading to nitrite accumulation in a hypertrophic marine fish culture system. Mar. Ecol-Prog. Ser. 181, 97-106. https://doi.org/10.3354/meps181097

Funes-Rodríguez R., Gómez-Gutiérrez J. y PalomaresGarcía R. (2007). Estudios ecológicos en Bahía Magdalena. Instituto Politécnico Nacional, La Paz, México, $311 \mathrm{pp}$.

Gardiner J. y Stiff M.J. (1975). The determination of cadmium, lead, copper and zinc in ground water, estuarine water, sewage and sewage effluent by anodic stripping voltammetry. Water Res. 9 (5-6), 517-523. https://doi. org/10.1016/0043-1354(75)90077-9

González-Soto E. (2017). Geoquímica de elementos mayores y traza en sedimentos mde la cuenca hidrográfica Las Bramonas, Baja California Sur, México. Tesis de Maestría. Centro Interdisciplinario de Ciencias Marinas, Instituto Politécnico Nacional, Baja California Sur, México, 70 pp.

Jeffrey S. y Humphrey J. (1975). New spectrophotometric equations for determining Chlorophylls a, b, c1 and c2 in algal phytoplankton and higher plants. Biochem. Physiol. Pfl. 167, 191-194. https://doi.org/10.1016/ S0015-3796(17)30778-3

Jiménez-Quiroz M.C., Cervantes-Duarte R., FunesRodríguez R., Barón-Campis S.A., García-Romero F.J., Hernández-Trujillo S., Hernández-Becerril D.U., González-Armas R., Martell-Dubois R., CerdeiraEstrada S., Fernández-Méndez J.I., González-Ania L.V., Vásquez-Ortiz M. y Barrón-Barraza F.J. (2019) Impact of "The Blob" and "El Niño" in the SW Baja California Peninsula: Plankton and environmental variability of Bahia Magdalena. Front. Mar. Sci. 6 (25). https://doi.org/10.3389/fmars.2019.00025

Lares M.L., Marinone S.G., Rivera-Duarte I., Beck A. y Sañudo-Wilhelmy S. (2009). Spatial variability of trace metals and inorganic nutrients in surface waters of Todos Santos Bay, México in the summer of 2005 during a red tide algal bloom. Arch. Environ. Con. Tox. 56 (4), 707-716. https://doi.org/10.1007/s00244-008-9210-x

Libes S.M. (2009). Introduction to marine biogeochemistry. 2a ed. Academic Press, California, EUA, 734 pp.

Lluch-Belda D., Hernández-Rivas M.E., Saldierna-Martínez R. y Guerrero-Caballero R. (2000). Variabilidad de la temperatura superficial del mar en Bahía Magdalena, B.C.S. Oceánides 15 (1), 1-23. 
Martínez-LópezA. y Verdugo-Díaz G. (2000). Composición y dinámica del fitoplancton en El CAB de Bahía Magdalena, B.C.S. En: BAC Centros de actividad biológica del Pacífico mexicano (Lluch-Belda D., Elorduy-Garay J., Lluch-Cota S.E. y Ponce Díaz G., Eds.). Centro de Investigaciones Biológicas del Noroeste, SC, La Paz, Baja California Sur, México, pp. 125-142.

Parsons T.R., Maita Y. y Lalli C.M. (1984). A manual of chemical \& biological methods for seawater analysis. Pergamon Press, Oxford, Reino Unido, 173 pp.

PMSMB-CBCS (2009). Estudio inicial para la clasificación sanitaria de las áreas de cultivo y extracción silvestre de moluscos bivalvos del complejo lagunar de Bahía Magdalena-Bahía Almejas, en el Municipio de Comondú (junio 2007 a marzo del 2009). Programa Mexicano de Sanidad de Moluscos Bivalvos, Comité Baja California Sur, México, 93 pp.

PMSMB-CBCS (2013). Estudio sanitario para la reclasificación de las áreas de cultivo y extracción silvestre de moluscos bivalvos del complejo lagunar Bahía Magdalena-Bahía Almejas, en el municipio de Comondú (octubre 2013-junio 2014). Programa Mexicano de Sanidad de Moluscos Bivalvos, Comité Baja California Sur, 39 pp.

PMSMB-CBCS (2015). Estudio para la reclasificación sanitaria de las áreas de cultivo y extracción silvestre de moluscos bivalvos del complejo lagunar Bahía Magdalena-Bahía Almejas, en el municipio de Comondú (noviembre 2015-abril 2018). Programa Mexicano de Sanidad de Moluscos Bivalvos, Comité Baja California Sur, México, 45 pp.

Rábago-Quiroz C.H., García-Borbón J.A., Palacios-Salgado D.S. y Barrón-Barraza F.J. (2017). Length-weight relation for eleven demersal fish species in the artisanal shrimp fishery áreas from the Bahia MagdalenaAlmejas lagoon system, Mexico. Acta Ichthyol. Piscat. 47 (3), 303-305. https://doi.org/10.3750/AIEP/02186

Raven J.A., Evans M.C.W. y Korb R.E. (1999). The role of trace metals in photosynthetic electron transport in $\mathrm{O}_{2}$-evolving organisms. Photosynth. Res. 60, 111-149. https://doi.org/10.1023/A:1006282714942

Robinson C. (2016). Evolution of the 2014-2015 sea surface temperature warming in the central west coast of Baja California, Mexico, recorded by remote sensing: The warm anomaly in Baja California. Geophys. Res. Lett. 43, 7066-7071. https://doi. org/10.1002/2016GL069356

Rodríguez-Meza G.D., Choumiline E., Méndez-Rodríguez L., Acosta-Vargas B. y Sapozhnikov D. (2007). Composición química de los sedimentos y macroalgas del complejo lagunar Magdalena-Almejas. En: Estudios ecológicos en Bahía Magdalena (Funes-Rodríguez R., Gómez-Gutiérrez J. y Palomares-García R., Eds.).
Instituto Politécnico Nacional, La Paz, México, pp. 61-82.

Rudnick R.L. y Gao S. (2003). Composition of the continental crust. Treatise on Geochemistry 1 (7), 1-64. https://doi.org/10.1016/B0-08-043751-6/03016-4

Russell-Flegal A., y Sañudo-Wilhelmy S. (1993). Comparable levels of trace metal contamination in two semienclosed embayments: San Diego Bay and South San Francisco Bay. Environ. Sci. Technol. 27, 1934-1936. https://doi.org/10.1021/es00046a025

Santos-Echeandia J., Prego R., Cobelo-García A. y Millward G.E. (2009a). Porewater geochemistry in a Galician Ria (NW Iberian Peninsula): Implications for benthic fluxes of dissolved trace elements $(\mathrm{Co}, \mathrm{Cu}, \mathrm{Ni}$, Pb, V, Zn). Mar. Chem. 117 (1-4), 77-87. https://doi. org/10.1016/j.marchem.2009.05.001

Santos-Echeandia J., Prego R. y Cobelo-García A. (2009b). Intra-annual variation and baseline concentrations of dissolved trace metals in the Vigo Ria and adjacent coastal waters (NE Atlantic Coast). Mar. Pollut. Bull. 58 (2), 298-303. https://doi.org/10.1016/j.marpolbul.2008.10.012

Santos-Echeandia J. (2011). Direct simultaneous determination of $\mathrm{Co}, \mathrm{Cu}, \mathrm{Fe}, \mathrm{Ni}$ and $\mathrm{V}$ in pore waters by means of adsorptive cathodic stripping voltammetry with mixed ligands. Talanta 85 (1), 506-512. https:// doi.org/10.1016/j.talanta.2011.04.035

Sañudo-Wilhelmy S. y Russell-Flegal A. (1989). Trace element distributions in coastal waters along the US-Mexican boundary: Relative contributions of natural processes vs. anthropogenic inputs. Mar. Chem. 33, 371-392. https://doi.org/10.1016/03044203(91)90078-B

Sañudo-Wilhelmy S. y Russell-Flegal A. (1996). Trace metal concentrations in the surf zone and in coastal waters off Baja California, Mexico. Environ. Sci. Technol. 30, 1575-1580. https://doi.org/10.1021/es9505560

SEDUE (1989). Criterios ecológicos de calidad del agua CE-CCA-001/89. Secretaría de Desarrollo Urbano y Ecología, Instituto de Ecología, México. Diario Oficial de la Federación, 13 de diciembre.

SEMARNAT (1997). Norma Oficial Mexicana NOM001-CNA-1996. Que establece los niveles máximos permisibles de contaminantes en las descargas de aguas residuales y bienes nacionales. Secretaría de Medio Ambiente, Recursos Naturales y Pesca. Diario Oficial de la Federación, 6 de enero.

Shumilin E., Rodríguez-Meza G.D., Sapozhnikov D., Lutsarev S. y Murrillo de Nava J. (2005). Arsenic concentrations in the surface sediments of the MagdalenaAlmejas Lagoon Complex, Baja California Peninsula, Mexico. B. Environ. Contam. Tox. 74, 493-500. https:// doi.org/10.1007/s00128-005-0612-4 
SSA (1973). Reglamento para la prevención y control de la contaminación de las aguas. Secretaría de Salud. Diario Oficial de la Federación, 29 de marzo.

Strickland D.H. y Parsons T.R. (1972). A practical handbook of seawater analysis. Bulletin 167. 2a ed. Fisheries Research Board of Canada, Ottawa, Canadá, $310 \mathrm{pp}$.

Sujitha S.B., Jonathan M.P., Escobedo-Urías D.C., Aguirre-Bahena F., Campos-Villegas L.E. y MuñozSevilla N.P. (2017). Spatial variability of inorganic nutrients and physical parameters in the waters of Bahia Magdalena lagoon, Pacific Coast, Mexico. Acta Ecol. Sin. 37 (3), 187-194. https://doi.org/10.1016/j. chnaes.2017.01.003

Sunda W.G. y Huntsman S.A. (1995). Cobalt and zinc interplacement in marine phytoplankton: Biological and geochemical implications. Limnol. Oceanogr. 40, 1404-1417. https://doi.org/10.4319/lo.1995.40.8.1404

Trezzi G., García-Orellana J., Rodellas V., Santos-Echeandia J., Tovar-Sánchez A., García-Solsona E. y Masqué P.
(2016). Submarine groundwater discharge: A significant source of dissolved trace metals to the North Western Mediterranean Sea. Mar. Chem. 186, 90-100. https://doi.org/10.1016/j.marchem.2016.08.004

Venrick E. y Hayward T. (1984). Determining chlorophyll on the $1984 \mathrm{CalCOFI}$ surveys. CalCOFI Reports 25, 74-79.

Weiss R.F. (1970). The solubility of nitrogen, oxygen and argon in water and seawater. Deep-Sea Res. 17, 721735. https://doi.org/10.1016/0011-7471(70)90037-9

Zárate-Ovando B., Palacios E., Reyes-Bonilla H., Amador E. y Saad G. (2006). Waterbirds of the lagoon complex Magdalena Bay-Almejas, Baja California Sur, Mexico. Waterbirds 29, 350-364. https://doi.org/10.1675/15244695(2006)29[350:WOTLCM]2.0.CO;2

Zaytsev O. y Cervantes-Duarte R. (2018). Nutrient flux estimates in a tidal basin: A case study of Magdalena lagoon, Mexican Pacific coast. Estuar. Coast. Shelf S. 207, 16-29. https://doi.org/10.1016/j. ecss.2018.03.013 